\title{
Epworth sleepiness scale in medical residents: quality of sleep and its relationship to quality of life
}

\author{
Yehia Z. Alami', Beesan T. Ghanim ${ }^{1}$ and Sa'ed H. Zyoud ${ }^{2,3^{*}}$
}

\begin{abstract}
Background: Resident doctors are continuously exposed to prolonged working hours and night shifts, making them susceptible to the many physical, psychological, and cognitive side effects of sleep deprivation, which may affect their quality of life. Therefore, this study aimed to determine the prevalence of sleep penury in resident doctors and to assess the association between self-apprehended sleepiness and quality of life.

Methods: A cross-sectional study was carried out in the governmental hospitals in the North of the West Bank between May 2017 and September 2017. Doctors enrolled in residency programmes completed questionnaires about general, sociodemographic, and sleep characteristics. The doctors completed the Arabic Version of the Epworth Sleepiness Scale (ArESS) to assess subjective daytime sleepiness and the RAND 36-item short-form health survey (SF-36) to determine quality of life.

Results: A total of 101 participants were enrolled. Daytime sleepiness was observed in 37.6\% ( $n=38)$ of the participants with an ESS score of $\geq 10$. There was a notable negative correlation between the ESS and quality of health index in the physical composition $(r=-0.351, p<0.001)$ demonstrated in the following four subscales: the physical functioning $(p<0.001)$, role limitations due to physical health $(p=0.045)$, body pain $(p=0.036)$, and general health $(p<0.001)$ components of the SF-36 scale. Females and residents of the centre region had poorer mental quality ( $p=0.006$ and 0.020 , respectively).

Conclusions: More than one third of the resident doctors suffer from daytime sleepiness according to the ESS. This was proven to significantly affect several aspects of their quality of life, including physical function and health, body pain, and general health. Sleep deprivation and improvement of quality of life require health promotion actions among medical residents.
\end{abstract}

Keywords: Residents, Epworth, Sleepiness, Quality of life, SF-36

\section{Background}

According to many articles, sleep deprivation affects many physiological and psychological aspects of one's life [1-3]. Sleep deprivation affects episodic memory as well as self-awareness and responsibility [3-5]. Sleep loss also severely affects the emotional memory in its contextual and non-contextual aspects [6]. Neuronal

\footnotetext{
* Correspondence: saedzyoud@yahoo.com; saedzyoud@najah.edu ${ }^{2}$ Poison Control and Drug Information Center (PCDIC), College of Medicine and Health Sciences, An-Najah National University, Nablus 44839, Palestine ${ }^{3}$ Department of Clinical and Community Pharmacy, Department of Pharmacy, College of Medicine and Health Sciences, An-Najah National University, Nablus 44839, Palestine

Full list of author information is available at the end of the article
}

apoptosis using adrenergic receptors can be triggered due to the deprivation of rapid eye movement (REM) sleep component [7], as well as induce anxiolytic-like effects by dopaminergic influences [8]. According to De Bernardi Rodrigues et al., sleep deprivation is associated with decreased sensitivity to insulin and centripetal distribution of fat in adolescence [9].

One of the many professions that is continuously exposed to prolonged periods of sleep deprivation is that of a resident doctor. The prolonged working hours of resident physicians make them vulnerable to the consequences of sleep penury, which affects their task performance and quality of life [10]. The residents' poor 
sleep quality is associated with increased body mass index (BMI), poorer lipid profile, poor quality of food consumed, and increase in waist circumference [11]. The nature of this poor sleep may also affect the residents psychologically by making them depressed, anxious, and insomnious [12-14]. Immune function has also been studied in relation to poor sleep quality, indicating the probability of inflammatory responses, triggered by short sleep duration, producing metabolic, respiratory, and cardiovascular diseases. In addition, it has been reported that poor sleep might cause elevated $\mathrm{C}$-reactive protein levels, an inflammatory marker for cardiovascular diseases [10, 15].

Several studies have demonstrated how sleep deprivation negatively impacts one's well-being in general and how it negatively influences resident doctors specifically $[3,5,10,12-14,16,17]$. However, to our knowledge, little is known about the effects of daytime sleepiness on residents' health [16]. Although limited studies have been conducted and published about sleep habits and problems among Palestinian university students $[18,19]$, Palestinian patients diagnosed with cancer [20], and the Palestinian population [21], no studies have been conducted to focus on the relationship between self-reported sleepiness, as surrogate marker of poor sleep, and quality of life in resident doctors in Palestine. Therefore, the purposes of this investigation are to determine the prevalence of self-reported sleepiness in resident doctors and to assess the association between sleepiness and their quality of life. The significance of this study may be reflected in the rules and policies of the Ministry of Health by proposing new working hours, changing on-call guidelines and duties, strengthening the on-call team, improving sleeping places to promote better sleep hygiene, offering free times for taking naps [16, 22], providing stress-relieving activities, and adopting rewarding programmes i.e. providing extra money and increasing residents' days-off to galvanise the resident physicians.

\section{Methods}

\section{Study design and population}

A cross-sectional study design was employed to achieve the research objectives. The study took place amongst a group of health care practitioners, as it included resident doctors who are training in different specialities. Resident doctors who are general practitioners were excluded because they are not in the medical training (residency) programme.

\section{Setting}

The data were collected from governmental hospitals in three cities in the North of the West Bank (Jenin, Nablus, and Tulkarm). These hospitals are the sites of the medical training programme for the resident doctors in North of the West Bank.

\section{Sample size and sampling technique}

The estimated number of resident doctors licensed by the Palestinian Medical Association who worked at the surveyed hospitals was around 130. Accordingly, the Raosoft sample size calculator was used to perceive the sample size [23] by keeping an indicator percentage of 0.50 , a margin of error of $5 \%$, and a confidence interval of $95 \%$. The calculated sample size was 98 . Between May 2017 and September 2017, we enrolled a convenience sample of 126 resident doctors.

\section{Data collection}

The doctors completed surveys about their sociodemographic, general, and sleep characteristics. Sociodemographic and general characteristics included age, sex, marital status, governorates they come from in the West Bank (north, central, south), who they live with (with family or not), BMI and change in weight during residency, presence of chronic diseases, place of graduation, working department, number of residency years, and years of work experience. Sleep characteristics included questions about sleeping hours on days with and without shifts, caffeine intake, smoking, use of sleeping pills, time to fall asleep, and waking up during sleep.

\section{Instruments}

Physicians were asked to complete two instruments: the Arabic Version of the Epworth sleepiness scale (ArESS) to assess the quality of sleep and the RAND 36-item short-form health survey (SF-36).

\section{Arabic Version of the Epworth sleepiness scale (ArESS)}

The Epworth Sleepiness Scale (ESS) was developed to assess sleepiness during daytime. The ESS questionnaire consists of eight questions about daily situations that can induce sleepiness. Each question has the lowest score of 0 ('no chance of falling asleep') to 3 ('high chance of falling asleep'). The score ranges can sum up to 24 and are categorised as normal $(E S S<10)$ or positive for daytime sleepiness $(E S S \geq 10)$ [24]. We used the ArESS, which has been validated and is reliable to be used in populations that are Arabic-speaking [25]. Permission to use the ArESS was given by Professor Hamdan Al-Jahdali via e-mail correspondence. There is a high level of internal consistency within the ArESS in our study, as measured by Cronbach's alpha (0.749).

\section{RAND 36-item short-form health survey (SF-36)}

This survey was employed to discern the general quality of life based on the previous one month's experiences [26]. It consists of 36 items divided into subscales, each 
Table 1 Sociodemographic and general characteristics

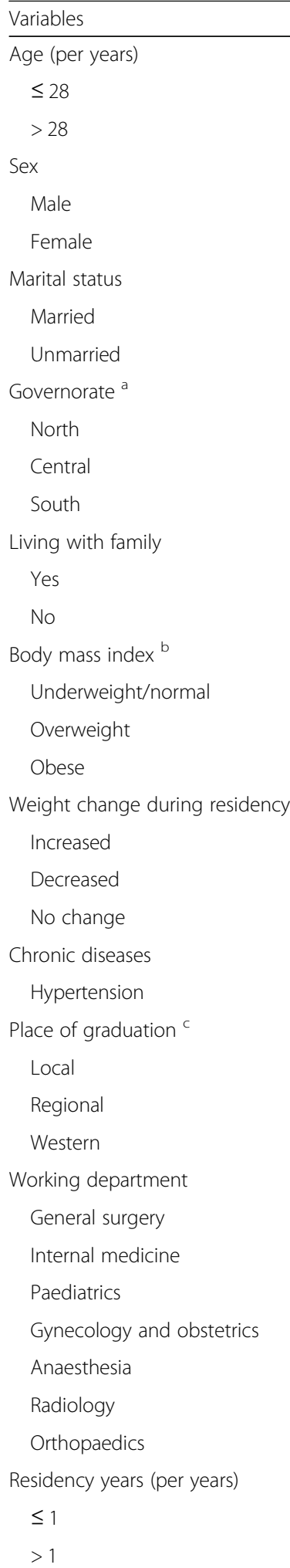

n (\%)

60(59.4)

$41(40.6)$

86(85.1)

15(14.9)

48(47.5)

53(52.5)

79(78.2)

$5(5.0)$

$17(16.8)$

$79(78.2)$

22(21.8)

39(38.6)

$50(49.5)$

12(11.9)

39(38.6)

$27(26.7)$

$35(34.7)$

3(3.0)

28(27.7)

52(51.5)

$21(20.8)$

23(22.8)

$11(10.9)$

22(21.8)

14(13.9)

11(10.9)

7(6.9)

13(12.9)

$37(36.6)$

64(63.4)
Table 1 Sociodemographic and general characteristics

(Continued)

\begin{tabular}{|c|c|}
\hline Variables & n (\%) \\
\hline \multicolumn{2}{|c|}{ Years of experience (per years) } \\
\hline$\leq 2$ & $33(32.7)$ \\
\hline $3-4$ & $41(40.6$ \\
\hline$>4$ & $27(26.7$ \\
\hline \multicolumn{2}{|c|}{$\begin{array}{l}n \text { frequency, SD standard deviation, } \% \text { percentage } \\
\text { a Governorates: North (Jenin, Nablus, Tulkarm, Qalqilya, Salfit, Tubas), Central } \\
\text { (Jerusalem, Ramallah), South (Bethlehem, Hebron) } \\
\text { b Body mass index: Underweight/normal }(\leq 24) \text {, overweight }(>24-<30) \text {, } \\
\text { obese ( } \geq 30) \\
{ }^{c} \text { Place of graduation: Local (Palestine), regional (Arab-world countries other } \\
\text { than Palestine), western (remaining countries worldwide) }\end{array}$} \\
\hline
\end{tabular}

with its own score: physical functioning (PF), role limitations due to physical health (RP), bodily pain (BP), general health $(\mathrm{GH})$, role limitations due to emotional problems (RE), vitality/energy and fatigue (VT), mental health $(\mathrm{MH})$, social functioning (SF), and health change in the past year (HC). We categorised the first four components to yield the physical composite score and the latter four components to produce the mental composite score as Zhu et al. reported [27]. The scores varied between 0 and 100; the higher score, the better the quality of life is [28]. We used the Arabic model of the inquiry, which is valid and reliable [29]. Cronbach's alpha for all subscales of the SF-36 for our study exceed alpha of 0.70 . Face and content validity of the final version of instrument was discussed and evaluated by a panel of three researchers who are expert in research related to sleep and QOL for assessing the organization, appropriateness meaning of terms, clinical terminology, completeness, and logical sequence of the statements.

Table 2 36-Item Short Form Health Survey (SF-36)

\begin{tabular}{ll}
\hline Variables & Mean \pm SD \\
\hline Physical functioning & $80.2 \pm 22.3$
\end{tabular}

Role limitations due to physical health

$61.9 \pm 38.2$

Role limitations due to emotional problems

$45.9 \pm 42.9$

Energy/fatigue

$39.6 \pm 16.7$

Emotional well-being

$50.6 \pm 18.8$

Social functioning

$49.9 \pm 24.7$

Pain

$68.7 \pm 22.7$

General health

$61.0 \pm 17.2$

Health change

$42.1 \pm 19.7$

PCS

$67.9 \pm 19.9$

MCS

$46.4 \pm 19.6$

Average total

$55.5 \pm 16.4$

$n$ frequency, $S D$ standard deviation, \% percentage, $P C S$ physical composite score, MCS mental composite score 
Table 3 PCS and MCS according to sociodemographic and general characteristics

\begin{tabular}{|c|c|c|c|c|c|}
\hline & $\mathrm{n}(\%)$ & PCS Median [Q1-Q3] & $p$ value $^{\mathrm{d}}$ & MCS Median [Q1-Q3] & $p$ value $^{d}$ \\
\hline \multicolumn{6}{|l|}{ Age (per years) } \\
\hline$\leq 28$ & $60(59.4)$ & $70.4[50.2-87.4]$ & \multirow[t]{2}{*}{$0.849^{e}$} & $41.0[28.3-61.9]$ & \multirow[t]{2}{*}{$0.424^{e}$} \\
\hline$>28$ & $41(40.6)$ & $72.0[52.5-85.0]$ & & $44.3[33.0-65.5]$ & \\
\hline \multicolumn{6}{|l|}{ Sex } \\
\hline Male & $86(85.1)$ & 71.6[51.7-87.1] & \multirow[t]{2}{*}{$0.369^{e}$} & $45.3[32.2-64.6]$ & \multirow[t]{2}{*}{$0.006^{\mathrm{e}}$} \\
\hline Female & $15(14.9)$ & $62.0[49.5-80.0]$ & & $28.0[20.3-41.5]$ & \\
\hline \multicolumn{6}{|l|}{ Marital status } \\
\hline Married & $48(47.5)$ & $57.5[48.9-87.1]$ & \multirow[t]{2}{*}{$0.570^{e}$} & $41.5[31.3-62.6]$ & \multirow[t]{2}{*}{$0.957^{e}$} \\
\hline Unmarried & $53(52.5)$ & $72.0[52.3-86.0]$ & & $44.0[28.1-64.0]$ & \\
\hline \multicolumn{6}{|l|}{ Governorate $^{a}$} \\
\hline North & $79(78.2)$ & $72.0[52.5-85.8]$ & & $42.0[28.3-62.0]$ & \multirow[t]{3}{*}{$0.020^{f}$} \\
\hline Central & $5(5.0)$ & $48.3[36.6-82.9]$ & & $24.0[17.4-37.5]$ & \\
\hline South & $17(16.8)$ & $70.0[46.9-89.8]$ & $0.512^{f}$ & $59.0[35.3-70.1]$ & \\
\hline \multicolumn{6}{|l|}{ Living with family } \\
\hline Yes & $79(78.2)$ & $72.0[52.0-87.0]$ & \multirow[t]{2}{*}{$0.103^{e}$} & $44.8[28.3-65.3]$ & \multirow[t]{2}{*}{$0.248^{e}$} \\
\hline No & $22(21.8)$ & $58.5[45.9-77.5]$ & & $39.0[28.4-49.9]$ & \\
\hline \multicolumn{6}{|l|}{ Body mass index ${ }^{b}$} \\
\hline Underweight/normal & $39(38.6)$ & $70.8[51.3-88.3]$ & \multirow[t]{3}{*}{$0.368^{f}$} & $41.5[27.0-64.5]$ & \multirow[t]{3}{*}{$0.899^{f}$} \\
\hline Overweight & $50(49.5)$ & $73.5[52.5-86.6]$ & & $42.6[32.1-63.1]$ & \\
\hline Obese & $12(11.9)$ & $56.3[47.4-78.0]$ & & $43.6[31.8-61.9]$ & \\
\hline \multicolumn{6}{|l|}{ Weight change during residency } \\
\hline Increased & $39(38.6)$ & $72.5[49.5-88.3]$ & \multirow[t]{3}{*}{$0.238^{f}$} & $49.5[32.0-67.3]$ & \multirow[t]{3}{*}{$0.147^{f}$} \\
\hline Decreased & $27(26.7)$ & $59.5[48.3-80.8]$ & & $36.3[26.3-59.0]$ & \\
\hline No change & $35(34.7)$ & $72.0[52.5-88.8]$ & & $44.8[32.0-65.3]$ & \\
\hline \multicolumn{6}{|l|}{ Place of graduation ${ }^{c}$} \\
\hline Local & $28(27.7)$ & $70.0[51.6-86.7]$ & \multirow[t]{3}{*}{$0.085^{f}$} & $41.4[26.4-57.6]$ & \multirow[t]{3}{*}{$0.130^{f}$} \\
\hline Regional & $52(51.5)$ & $64.4[47.1-82.8]$ & & $40.4[28.3-64.1]$ & \\
\hline Western & $21(20.8)$ & $82.5[62.6-90.4]$ & & $51.3[40.4-68.9]$ & \\
\hline \multicolumn{6}{|l|}{ Working department } \\
\hline General surgery & $23(22.8)$ & $62.5[50.0-86.3]$ & $0.156^{f}$ & $38.3[26.0-53.8]$ & $0.585^{f}$ \\
\hline Internal medicine & $11(10.9)$ & $87.0[60.8-90.0]$ & & $54.0[32.0-73.0]$ & \\
\hline Paediatrics & $22(21.8)$ & $59.1[48.4-78.4]$ & & 43.4[30.9-58.4] & \\
\hline Gynecology and obstetrics & $14(13.9)$ & $69.8[47.5-80.6]$ & & $35.9[27.8-65.6]$ & \\
\hline Anaesthesia & $11(10.9)$ & $85.8[74.5-95.0]$ & & $49.5[40.8-64.8]$ & \\
\hline Radiology & $7(6.9)$ & $72.0[52.5-83.3]$ & & $38.5[26.3-72.8]$ & \\
\hline Orthopaedics & $13(12.9)$ & $70.8[52.3-89.4]$ & & $48.8[35.4-67.0]$ & \\
\hline Residency years (per years) & & & & & \\
\hline$\leq 1$ & $37(36.6)$ & $72.0[50.4-88.1]$ & & $47.8[30.8-65.0]$ & $0.196^{e}$ \\
\hline$>1$ & $64(63.4)$ & $68.8[51.3-85.0]$ & $0.617^{e}$ & $41.0[28.3-58.1]$ & \\
\hline Years of experience (per years & & & & & \\
\hline$\leq 2$ & $33(32.7)$ & $72.0[51.0-88.1]$ & & $54.0[30.8-66.3]$ & $0.149^{f}$ \\
\hline $3-4$ & $41(40.6)$ & $60.8[49.1-82.5]$ & $0.116^{f}$ & $40.0[28.3-53.5]$ & \\
\hline$>4$ & $27(26.7)$ & $75.8[52.5-88.8]$ & & $41.0[27.8-71.0]$ & \\
\hline
\end{tabular}

$n$ frequency, \% percentage, $P C S$ physical composite score, MCS mental composite score

a Governorates: North (Jenin, Nablus, Tulkarm, Qalqilya, Salfit, Tubas), Central (Jerusalem, Ramallah), South (Bethlehem, Hebron)

${ }^{b}$ Body mass index: Underweight/normal $(\leq 24)$, overweight $(>24-<30)$, obese $(\geq 30)$

c Place of graduation: Local (Palestine), regional (Arab-world countries other than Palestine), western (remaining countries worldwide)

${ }^{d}$ The $p$-value is bold where it is less than the significance level cut-off of 0.05

e Statistical significance of differences calculated using the Mann-Whitney $U$ test

${ }^{f}$ Statistical significance of differences calculated using the Kruskal-Wallis test 
Table 4 Sleep characteristics

\begin{tabular}{ll}
\hline Variables & $\mathrm{n}(\%)$ \\
\hline Smoking & $40(39.6)$ \\
Caffeine use & $95(94.1)$ \\
Coffee (per ml) & $20(19.8)$ \\
None & $8(7.9)$ \\
Up to 100 & $22(21.8)$ \\
Up to 200 & $31(30.7)$ \\
Up to 300 & $20(19.8)$ \\
More than 300 & \\
Tea (per ml) & $34(33.7)$ \\
None & $33(32.7)$ \\
Up to 100 & $18(17.8)$ \\
Up to 200 & $11(10.9)$ \\
Up to 300 & $5(5.0)$ \\
More than 300 & \\
Energy drinks (per ml) & $87(86.1)$ \\
None & $6(5.9)$ \\
Up to 100 & $3(3.0)$ \\
Up to 200 & $5(5.0)$ \\
Up to 300 & \\
Caffeine at night (times per week) &
\end{tabular}

None

Once or twice

Three to four

More than four

Non-shift sleep hours

$$
\leq 4 \mathrm{~h}
$$

4-6 h

$\geq 6 \mathrm{~h}$

Shift sleep hours

$\leq 4 \mathrm{~h}$

4-6 h

$\geq 6 \mathrm{~h}$

Sleeping pills use

Time taken to fall asleep

$$
\leq 10 \text { mins }
$$

10-30 min

30-60 min

$>60$ mins

Waking up during sleep

Wake up to eat

Wake up due to noise

Sleep walking

Nightmares

16(15.8)

22(21.8)

5(5.0)

$61(60.4)$

35(34.7)

85(84.1)

14(13.9)

2(2.0)

$4(4.0)$

27(26.7)

35(34.7)

28(27.7)

$11(10.9)$

73(72.3)

17(16.8)

59(58.4)

$\mathrm{O}(0.0)$

51(50.5)
Table 4 Sleep characteristics (Continued)

\begin{tabular}{ll}
\hline Variables & $\mathrm{n}(\%)$ \\
\hline Epworth Sleepiness Scale & \\
$<10$ & $63(62.4)$ \\
$\geq 10$ & $38(37.6)$ \\
\hline
\end{tabular}

\section{Ethical approval}

All rules of conduct were authorised by the Institutional Review Boards (IRB) before initiation of this study, and permission to interview the medical residents was granted by the local health authorities.

\section{Statistical analysis}

All statistical analyses for our data were performed using the Statistical Package for Social Sciences version 15 (SPSS Inc., Chicago, IL, USA). Continuous data are presented as mean \pm standard deviation (SD) or median (Q1-Q3; interquartile range) or frequency (percentage) for categorical variables. Data were tested for normality using the Kolmogorov-Smirnov test. In comparing two groups, we used Mann-Whitney $U$ tests, and for comparing more than two groups, we used Kruskal-Wallis tests. We assessed the correlation between ESS and SF-36 domains using the Pearson's correlation coefficient; $p$ values $<0.05$ were considered significant. Internal consistency reliability for all scales was assessed using Cronbach's alpha.

\section{Results}

The characteristics of the resident doctors
Overall, 126 questionnaire were distributed, $112(88.8 \%)$ were returned, 101 (80.1\%) were accepted, and 11 (8.7\%) were rejected for incompleteness $(n=8)$ or for respondents being general practitioners $(n=3)$. Of the 101 participants, 86 were male $(85.1 \%)$ and 15 were female (14.9\%), with a mean age of $28.5 \pm 2.5$. Table 1 shows the sociodemographic and general characteristics of the participants.

\section{Health-related quality of life in the participant residents}

The means of the SF-36 subscales were calculated in Table 2, and the results, as shown in Additional file 1: Table S1 and Table S2, indicate a statistically significant difference in all of the subscale components with different variables at $p<0.05$ except for mental health, which showed no significance. As for physical functioning, there is significance with the years of experience $(p=$ 0.032). Role physical was significant in residents living with their family $(p=0.043)$. Role emotional shows significance with the residents' governorates $(p=0.042)$, years of residency $(p=0.004)$, and years of experience $(p=0.010)$. Vitality has significance with gender $(p=$ $0.019)$, age $(p=0.016)$, marital status $(p=0.021)$, and 
Table 5 Epworth Sleepiness Scale according to sociodemographic and general characteristics

\begin{tabular}{|c|c|c|c|}
\hline Variables & n (\%) & $\begin{array}{l}\text { ESS } \\
\text { Median [Q1-Q3] }\end{array}$ & $P$ value ${ }^{d}$ \\
\hline \multicolumn{4}{|l|}{ Age (per years) } \\
\hline$\leq 28$ & $60(59.4)$ & $9.0[5.0-11.0]$ & \multirow[t]{2}{*}{$0.670^{e}$} \\
\hline$>28$ & $41(40.6)$ & $8.0[6.5-11.0]$ & \\
\hline \multicolumn{4}{|l|}{ Sex } \\
\hline Male & $86(85.1)$ & $8.5[6.0-11.0]$ & \multirow[t]{2}{*}{$0.958^{\mathrm{e}}$} \\
\hline Female & 15(14.9) & $9.0[4.0-12.0]$ & \\
\hline \multicolumn{4}{|l|}{ Marital status } \\
\hline Married & $48(47.5)$ & $9.0[6.3-12.0]$ & \multirow[t]{2}{*}{$0.067^{e}$} \\
\hline Unmarried & $53(52.5)$ & $8.0[5.0-11.0]$ & \\
\hline \multicolumn{4}{|l|}{ Governorate $^{a}$} \\
\hline North & $79(78.2)$ & $9.0[6.0-11.0]$ & \multirow[t]{3}{*}{$0.861^{f}$} \\
\hline Central & $5(5.0)$ & $10.0[5.5-13.5]$ & \\
\hline South & $17(16.8)$ & $8.0[5.5-13.5]$ & \\
\hline \multicolumn{4}{|l|}{ Living with family } \\
\hline Yes & $79(78.2)$ & $8.0[5.0-11.0]$ & \multirow[t]{2}{*}{$0.063^{e}$} \\
\hline No & $22(21.8)$ & 10.0[7.0-12.3] & \\
\hline \multicolumn{4}{|l|}{ Body mass index ${ }^{b}$} \\
\hline Underweight/normal & 39(38.6) & $8.0[5.0-11.0]$ & \multirow[t]{3}{*}{$0.110^{f}$} \\
\hline Overweight & $50(49.5)$ & $9.0[7.0-12.0]$ & \\
\hline Obese & 12(11.9) & 7.0[4.5-11.8] & \\
\hline \multicolumn{4}{|l|}{ Weight change during residency } \\
\hline Increased & $39(38.6)$ & $9.0[6.0-12.0]$ & \multirow[t]{3}{*}{$0.300^{f}$} \\
\hline Decreased & $27(26.7)$ & $9.0[6.0-12.0]$ & \\
\hline No change & $35(34.7)$ & 7.0[5.0-11.0] & \\
\hline \multicolumn{4}{|l|}{ Place of graduation ${ }^{c}$} \\
\hline Local & $28(27.7)$ & $9.0[7.0-11.0]$ & \multirow[t]{3}{*}{$0.650^{f}$} \\
\hline Regional & $52(51.5)$ & $8.5[6.0-11.0]$ & \\
\hline Western & $21(20.8)$ & 7.0[4.0-11.5] & \\
\hline \multicolumn{4}{|l|}{ Working department } \\
\hline General surgery & $23(22.8)$ & $9.0[7.0-13.0]$ & \multirow[t]{7}{*}{$0.755^{f}$} \\
\hline Internal medicine & 11(10.9) & $8.0[4.0-9.0]$ & \\
\hline Paediatrics & $22(21.8)$ & $8.5[6.3-11.3]$ & \\
\hline Gynecology and obstetrics & 14(13.9) & $9.0[7.0-10.3]$ & \\
\hline Anaesthesia & $11(10.9)$ & $5.0[4.0-13.0]$ & \\
\hline Radiology & $7(6.9)$ & $8.0[5.0-11.0]$ & \\
\hline Orthopaedics & 13(12.9) & $9.0[4.0-11.5]$ & \\
\hline \multicolumn{4}{|l|}{ Residency years (per years) } \\
\hline$\leq 1$ & $37(36.6)$ & $8.0[4.0-11.0]$ & \multirow[t]{2}{*}{$0.064^{\mathrm{e}}$} \\
\hline$>1$ & $64(63.4)$ & $9.0[7.0-11.0]$ & \\
\hline
\end{tabular}

Table 5 Epworth Sleepiness Scale according to sociodemographic and general characteristics (Continued)

\begin{tabular}{|c|c|c|c|}
\hline Variables & n (\%) & $\begin{array}{l}\text { ESS } \\
\text { Median [Q1-Q3] }\end{array}$ & $P$ value ${ }^{d}$ \\
\hline \multicolumn{4}{|c|}{ Years of experience (per years) } \\
\hline$\leq 2$ & $33(32.7)$ & $8.0[4.0-10.0]$ & $0.243^{f}$ \\
\hline $3-4$ & $41(40.6)$ & $9.0[6.5-12.0]$ & \\
\hline$>4$ & $27(26.7)$ & $9.0[6.0-12.0]$ & \\
\hline
\end{tabular}

$n$ frequency, \% percentage, ESS Epworth Sleepiness Scale

${ }^{a}$ Governorates: North (Jenin, Nablus, Tulkarm, Qalqilya, Salfit, Tubas), Central (Jerusalem, Ramallah), South (Bethlehem, Hebron)

b Body mass index: Underweight/normal ( $\leq 24)$, overweight $(>24-<30$ ) obese $(\geq 30)$

c Place of graduation: Local (Palestine), regional (Arab-world countries other than Palestine), western (remaining countries worldwide)

${ }^{d}$ The $p$-value is bold where it is less than the significance level cut-off of 0.05

${ }^{\mathrm{e}}$ Statistical significance of differences calculated using the Mann-Whitney

$\mathrm{U}$ test

${ }^{f}$ Statistical significance of differences calculated using the Kruskal-Wallis test

place of graduation $(p=0.004)$. Social functioning is significant with gender $(p=0.006)$ and place of graduation $(p=0.049)$. Body pain is associated with change in weight during residency $(p=0.039)$ and the country of graduation $(p=0.005)$. General health is affected by the country of graduation $(p=0.022)$ and years of experience $(p=0.044)$. Health change is affected by weight change during residency $(p=0.023)$. On the other hand, as Table 3 shows, the mental composite score (MCS) was significant with gender $(p=0.006)$ and the governorates of the residents $(p=0.020)$; the physical composite score (PCS) had no apparent significance.

The sleep characteristics of the resident doctors

The sleep features of the participants are detailed in Table 4. The ESS median is 9 , and a score of $\geq 10$ indicating daytime sleepiness is observed in 38 (37.6\%) participants. The ESS is compared with sociodemographic and general characteristics to yield no significant association between them, as shown in Table 5. In comparing the ESS with the sleep characteristics, the only significant difference present is in having nightmares $(p=0.004)$, as Table 6 elaborates.

\section{Quality of health and sleepiness}

There is a significant correlation between sleepiness and quality of health among the residents as provided by the negative correlation between the ESS and the SF-36 scores of the physical functioning $(r=-0.397, p<0.001)$, role limitations due to physical health $(r=-0.200, p=$ $0.045)$, body pain $(r=-0.209, p=0.036)$, general health $(r=-0.392, p<0.001)$, and health change $(r=-0.199, p$ $=0.046)$ subscales, as shown in Additional file 1: Table S2. There are also significant positive correlations between the subscales of the SF-36 themselves as proved in Additional file 1: Table S2. This is also manifested in 
Table 6 Epworth Sleepiness Scale according to sleep characteristics

\begin{tabular}{|c|c|c|c|}
\hline Variables & n (\%) & $\begin{array}{l}\text { ESS } \\
\text { Median [Q1-Q3] }\end{array}$ & $P$ value ${ }^{a}$ \\
\hline \multicolumn{4}{|l|}{ Smoking } \\
\hline Yes & $40(39.6)$ & $9.0[5.3-11.8]$ & \multirow[t]{2}{*}{$0.728^{b}$} \\
\hline No & $61(60.4)$ & $8.0[6.0-11.0]$ & \\
\hline \multicolumn{4}{|l|}{ Coffee (per ml) } \\
\hline None & 20(19.8) & $7.5[6.3-9.8]$ & \multirow[t]{5}{*}{$0.222^{c}$} \\
\hline Up to 100 & $8(7.9)$ & $9.0[8.0-13.0]$ & \\
\hline Up to 200 & $22(21.8)$ & $8.5[6.5-12.0]$ & \\
\hline Up to 300 & $31(31.7)$ & $9.0[7.0-12.0]$ & \\
\hline More than 300 & 20(19.8) & $5.5[3.3-10.8]$ & \\
\hline \multicolumn{4}{|l|}{ Tea (per ml) } \\
\hline None & 34(33.7) & $8.0[4.0-11.3]$ & \multirow[t]{5}{*}{$0.145^{c}$} \\
\hline Up to 100 & $33(32.7)$ & $9.0[7.0-12.0]$ & \\
\hline Up to 200 & 18(17.8) & $8.0[4.3-11.3]$ & \\
\hline Up to 300 & $11(10.9)$ & $8.0[7.0-13.0]$ & \\
\hline More than 300 & $5(5.0)$ & $4.0[3.0-7.5]$ & \\
\hline \multicolumn{4}{|c|}{ Energy drinks (per ml) } \\
\hline None & $87(86.1)$ & $9.0[6.0-11.0]$ & \multirow[t]{4}{*}{$0.661^{c}$} \\
\hline Up to 100 & $6(5.9)$ & $8.0[3.5-14.3]$ & \\
\hline Up to 200 & $3(3.0)$ & $8.0[7.0-8.5]$ & \\
\hline Up to 300 & $5(5.0)$ & $7.0[2.0-10.0]$ & \\
\hline \multicolumn{4}{|c|}{ Caffeine at night (times per week) } \\
\hline No & $34(33.7)$ & $8.0[7.0-11.3]$ & \multirow[t]{4}{*}{$0.371^{c}$} \\
\hline Once or twice & $29(28.7)$ & $8.0[5.0-12.0]$ & \\
\hline Three to four & $16(15.8)$ & $9.0[7.5-11.0]$ & \\
\hline More than four & $22(21.8)$ & $7.0[4.0-10.3]$ & \\
\hline \multicolumn{4}{|c|}{ Non-shift sleep hours } \\
\hline$\leq 4 h$ & $5(5.0)$ & $11.0[7.5-14.0]$ & \multirow[t]{3}{*}{$0.297^{c}$} \\
\hline $4-6 h$ & $61(60.4)$ & $9.0[6.0-11.0]$ & \\
\hline$\geq 6 \mathrm{~h}$ & $35(34.7)$ & $8.0[4.0-10.0]$ & \\
\hline \multicolumn{4}{|l|}{ Shift sleep hours } \\
\hline$\leq 4 \mathrm{~h}$ & $85(84.1)$ & $8.0[6.0-11.0]$ & \multirow[t]{3}{*}{$0.568^{c}$} \\
\hline $4-6 h$ & 14(13.9) & $9.0[4.8-12.5]$ & \\
\hline$\geq 6 \mathrm{~h}$ & $2(2.0)$ & $6.5[5.0-8.0]$ & \\
\hline \multicolumn{4}{|l|}{ Sleeping pill use } \\
\hline Yes & $4(4.0)$ & $13.5[4.0-15.5]$ & \multirow[t]{2}{*}{$0.196^{b}$} \\
\hline No & $97(96.0)$ & $8.0[6.0-11.0]$ & \\
\hline \multicolumn{4}{|c|}{ Time taken to fall asleep } \\
\hline$\leq 10 \mathrm{mins}$ & $27(26.7)$ & $9.0[7.0-11.0]$ & \multirow[t]{4}{*}{$0.275^{c}$} \\
\hline $10-30 \mathrm{~min}$ & $35(34.7)$ & $8.0[6.0-11.0]$ & \\
\hline $30-60 \mathrm{~min}$ & $28(27.7)$ & $8.0[6.0-12.0]$ & \\
\hline$>60$ mins & $11(10.9)$ & $6.0[2.0-9.0]$ & \\
\hline
\end{tabular}

Table 6 Epworth Sleepiness Scale according to sleep characteristics (Continued)

\begin{tabular}{|c|c|c|c|}
\hline Variables & n (\%) & $\begin{array}{l}\text { ESS } \\
\text { Median [Q1-Q3] }\end{array}$ & $P$ value $^{a}$ \\
\hline \multicolumn{4}{|c|}{ Waking up during sleep } \\
\hline Yes & $73(72.3)$ & $9.0[6.0-11.0]$ & $0.741^{b}$ \\
\hline No & $28(27.7)$ & $8.5[4.8-12.8]$ & \\
\hline \multicolumn{4}{|c|}{ Wake up to eat } \\
\hline Yes & $17(16.8)$ & $9.0[7.0-12.0]$ & $0.492^{b}$ \\
\hline No & $84(83.2)$ & $8.5[5.3-11.0]$ & \\
\hline \multicolumn{4}{|c|}{ Wake up due to noise } \\
\hline Yes & $59(58.4)$ & $9.0[5.0-11.0]$ & $0.953^{b}$ \\
\hline No & $42(41.6)$ & $8.5[7.0-12.0]$ & \\
\hline \multicolumn{4}{|c|}{ Nightmares } \\
\hline Yes & $51(50.5)$ & $9.0[8.0-12.0]$ & $0.004^{b}$ \\
\hline No & $50(49.5)$ & $7.0[4.0-10.3]$ & \\
\hline
\end{tabular}

$n$ frequency, SD standard deviation, \% percentage, $\mathrm{m} /$ millilitres, $h$ hours, mins minutes

${ }^{a}$ The $p$-value is bold where it is less than the significance level cut-off of 0.05

b Statistical significance of differences calculated using the Mann-Whitney

$\mathrm{U}$ test

c Statistical significance of differences calculated using the Kruskal-Wallis test

correlating the ESS and PCS, as there is a significant negative correlation between them $(r=-0.351, p<0.001)$, unlike the ESS and MCS, where no significant correlation is present $(r=-0.097, p=0.334)$.

\section{Discussion}

This study aimed to assess the residents' sleepiness and their quality of life. Few studies have linked those two categories, and no such study has been conducted in Palestine. Hereby, valid Arabic models of both the SF-36 and the ESS were used to fulfill the purpose of this study $[25,30]$. The data gave the impression that medical residents may have reduced quality of both physical and mental health, but the results of this study were unanticipated regarding physical impairment. Our population may have had associations in some of the physical subscales with certain sociodemographic and general characteristics, but the PCS was unable to demonstrate so. Contrary to the insignificant result of the PCS in our study, a poor lipid profile and harmful lifestyle were exhibited among residents in Pikovsky et al. study, which may be reflected in their physical health [10]. This inconsistency may be due to the large number of residents in the same department and an unequal work load among them at the above-mentioned hospitals.

Regarding the participants' mental health, the MCS manifested a poorer mental status in residents coming from the central region (Ramallah and Jerusalem) and in female participants. Distance plays a role in this case, as residents from the central region usually do not take 
dormitories, unlike the southern population, according to Belayachi et al. [31].

Female doctors are more prone to mental health liability compared to male doctors, as indicated by Sundquist and Johansson [32].

Concerning the sleepiness of the participants, 38 (37.6\%) were sleepy by scoring 10 or more on the ESS, but, contrary to our expectation, having nightmares is surprisingly the only single factor between both the sociodemographic and sleep features to yield a significant relationship with the ESS. To support our result, Paul et al. elaborated that nightmares are associated with significantly decreased quality of sleep [33]. A systematic review by Bolster and Rourke found that in seven studies concerning shift hours, restriction had no influence on the residents' well-being, which could explain why there was no association between working hours and the ESS [34].

In the current study, correlating sleepiness with quality of life showed that daytime sleepiness leads to poor physical composite but, surprisingly, has an insignificant effect on the mental aspect according to the MCS. This finding is contrary to previous studies that suggested a worsening individual mood, depressive symptoms, and emotional exhaustion [17, 31].

Although this study is the first study of its kind to investigate the quality of life among resident doctors and their quality of sleep, several limitations that should be noted. First, the current study was limited by involving just the north of West Bank governmental hospitals i.e. Nablus, Jenin and Tulkarm, which led to a small sampling size, preventing generalisation. Second, being a cross-sectional type of study also made it difficult to know whether our outcome was affected prior to the residency period. Additionally, as a cross-sectional design was used, a causal relationship was difficult to infer. Third, the small number of female practitioners in the residency programmes is another drawback. Fourth, possibility that the scales were inaccurately filled in as they are self-reporting scales. Fifth, the exclusion of ophthalmology, otolaryngology, and emergency wards due to scarcity of residents also raised the susceptibility of bias. Sixth, ESS has low efficiency when used in evaluating sleepiness in general populations such as in our study [35, 36]. Finally, we did not use standardized and validated questionnaires to evaluate sleep quality and quantity; moreover sleep deprivation is evaluated only on number of hours of sleep and not by sleep logs or actigraphy. In this way none information is collected about possible co-occurrence of sleep disorders (e.g. snoring, obstructive sleep apnea, insomnia, restless legs syndrome etc) which may influence daytime sleepiness.

\section{Conclusions}

This paper has examined independently the qualities of life and sleep of West Bank medical residents working in the northern hospitals as well as the relationship between them. It appeared that female residents and those from the central region had poorer quality of life in the mental aspect. The paper also indicated increased sleepiness in participants who experience nightmares. Moreover, this study identified that daytime sleepiness impacts the residents physically, leading to a decreased quality of life. Daytime sleepiness and improvement of quality of life require health promotion actions among medical residents. Therefore, there is a definite need to enhance current policies regarding the residency programme schedule and, if needed, to further restrict working hours, and increasing the number of residents during each shift. One of the practical implications that can be made to ameliorate the residents' well-being is to promote better sleep hygiene by providing time and comfortable rooms for a nap, and stress-relief activities.

\section{Additional file}

Additional file 1: Table S1 and Table S2. SF-36 subscales scores according to sociodemographic and general characteristics, and Pearson correlation between Epworth Sleepiness Scale and SF-36 subscales. (DOC $114 \mathrm{~kb}$ )

\section{Abbreviations}

ArESS: Arabic Version of the Epworth Sleepiness Scale; BMI: Body mass index; BP: Bodily pain; ESS: Epworth sleepiness scale; GH: General health; HC: Health change in the past year; IRB: Institutional review board; MCS: Mental composite score; MH: Mental health; PCS: Physical composite score; PF: Physical functioning; Q1-Q3: Interquartile range; RE: Role limitations due to emotional problems; REM: Rapid eye movement; RP: Role limitations due to physical health; SD: Standard deviation; SF: Social functioning; SF-36: 36Item Short Form Health Survey; SPSS: Statistical Package for Social Sciences; VT: Vitality/energy and fatigue

\section{Acknowledgments}

Not applicable.

\section{Ethical approval and consent to participate}

All rules of conduct were authorised by the Institutional Review Boards (IRB) before initiation of this study, and permission to interview the medical residents was granted by the local health authorities. All study participants were informed about the purpose of the research and we obtained verbal consent from each participant.

\section{Availability of data and materials}

The raw data of this research can be made available upon request from the corresponding author

\section{Authors' contributions}

YA, and BG collected data, performed the analysis and wrote the draft manuscript. Searched the literature, and drafted the manuscript. SZ conceptualised and designed the study, coordinated, supervised, advised on data analysis and reviewed the manuscript, and assisted in the final write-up of the manuscript. All authors read and approved the final manuscript.

Consent for publication Not applicable.

Competing interests

The authors declare that they have no competing interests. 


\section{Publisher's Note}

Springer Nature remains neutral with regard to jurisdictional claims in published maps and institutional affiliations.

\section{Author details}

'Department of Medicine, College of Medicine and Health Sciences, An-Najah National University, Nablus 44839, Palestine. ${ }^{2}$ Poison Control and Drug Information Center (PCDIC), College of Medicine and Health Sciences, An-Najah National University, Nablus 44839, Palestine. ${ }^{3}$ Department of Clinical and Community Pharmacy, Department of Pharmacy, College of Medicine and Health Sciences, An-Najah National University, Nablus 44839, Palestine.

Received: 7 February 2018 Accepted: 3 July 2018

Published online: 13 July 2018

\section{References}

1. Saxena AD, George CF. Sleep and motor performance in on-call internal medicine residents. Sleep. 2005;28(11):1386-91.

2. Ayalon RD, Friedman F Jr. The effect of sleep deprivation on fine motor coordination in obstetrics and gynecology residents. Am J Obstet Gynecol. 2008;199(5):576. e1-5

3. Hamui-Sutton L, Barragan-Perez V, Fuentes-Garcia R, Monsalvo-Obregon EC, Fouilloux-Morales C. Sleep deprivation effects on cognitive, psychomotor skills and its relationship with personal characteristics of resident doctors. Cir Cir. 2013;81(4):317-27.

4. Wang L, Chen Y, Yao Y, Pan Y, Sun Y. Sleep deprivation disturbed regional brain activity in healthy subjects: evidence from a functional magnetic resonance-imaging study. Neuropsychiatr Dis Treat. 2016;12:801-7.

5. Kim HJ, Kim JH, Park KD, Choi KG, Lee HW. A survey of sleep deprivation patterns and their effects on cognitive functions of residents and interns in Korea. Sleep Med. 2011;12(4):390-6

6. Tempesta D, Socci V, Coppo M, Dello loio G, Nepa V, De Gennaro L, et al. The effect of sleep deprivation on the encoding of contextual and non-contextual aspects of emotional memory. Neurobiol Learn Mem. 2016;131:9-17.

7. Somarajan BI, Khanday MA, Mallick BN. Rapid eye movement sleep deprivation induces neuronal apoptosis by noradrenaline acting on Alpha1 adrenoceptor and by triggering mitochondrial intrinsic pathway. Front Neurol. 2016;7:25

8. Noseda AC, Targa AD, Rodrigues LS, Aurich MF, Lima MM. REM sleep deprivation promotes a dopaminergic influence in the striatal MT2 anxiolytic-like effects. Sleep Sci. 2016;9(1):47-54.

9. De Bernardi Rodrigues AM, da Silva Cde C, Vasques AC, Camilo DF, Barreiro F, Cassani RS, et al. Association of Sleep Deprivation with Reduction in insulin sensitivity as assessed by the hyperglycemic clamp technique in adolescents. JAMA Pediatr. 2016;170(5):487-94.

10. Pikovsky O, Oron M, Shiyovich A, Perry ZH, Nesher L. The impact of sleep deprivation on sleepiness, risk factors and professional performance in medical residents. Isr Med Assoc J. 2013:15(12):739-44.

11. Mota MC, Waterhouse J, De-Souza DA, Rossato LT, Silva CM, Araujo MB, et al. Sleep pattern is associated with adipokine levels and nutritional markers in resident physicians. Chronobiol Int. 2014:31(10):1130-8.

12. Johnson EO, Roth T, Breslau N. The association of insomnia with anxiety disorders and depression: exploration of the direction of risk. J Psychiatr Res. 2006;40(8):700-8

13. Al-Maddah EM, Al-Dabal BK, Khalil MS. Prevalence of sleep deprivation and relation with depressive symptoms among medical residents in king Fahd university hospital, Saudi Arabia. Sultan Qaboos Univ Med J. 2015;15(1):e78-84.

14. Min AA, Sbarra DA, Keim SM. Sleep disturbances predict prospective declines in resident physicians' psychological well-being. Med Educ Online. 2015;20:28530.

15. Meier-Ewert HK, Ridker PM, Rifai N, Regan MM, Price NJ, Dinges DF, et al. Effect of sleep loss on C-reactive protein, an inflammatory marker of cardiovascular risk. J Am Coll Cardiol. 2004;43(4):678-83.

16. Belayachi J, Benjelloun O, Madani N, Abidi K, Dendane T, Zeggwagh AA, et al. Self-perceived sleepiness in emergency training physicians: prevalence and relationship with quality of life. J Occup Med Toxicol. 2013:8(1):24

17. Wali SO, Qutah K, Abushanab L, Basamh R, Abushanab J, Krayem A. Effect of on-call-related sleep deprivation on physicians' mood and alertness. Ann Thorac Med. 2013;8(1):22-7.
18. Sweileh WM, Ali IA, Sawalha AF, Abu-Taha AS, Zyoud SH, Al-Jabi SW. Sleep habits and sleep problems among Palestinian students. Child Adolesc Psychiatry Ment Health. 2011;5(1):25.

19. Sweileh WM, Ali I, Sawalha AF, Abu-Tah AS, Zyoud SH, Al-Jabi SW. Gender differences in sleep habits and sleep-related problems in Arab Palestinian university students. Int J Disabil Hum Dev. 2012;11(3):289-93.

20. Dreidi MM, Hamdan-Mansour AM. Pain, sleep disturbance, and quality of life among Palestinian patients diagnosed with Cancer. J Cancer Educ. 2016;31(4):796-803.

21. El-Kharoubi AR. Sleep disorders and excessive daytime sleepiness in the Palestinian population. Neurosciences (Riyadh). 2004;9(1):46-8.

22. McDonald J, Potyk D, Fischer D, Parmenter B, Lillis T, Tompkins $L$, et al. Napping on the night shift: a study of sleep, performance, and learning in physicians-in-training. J Grad Med Educ. 2013;5(4):634-8.

23. Raosoft. Sample Size Calculator. http://www.raosoft.com/samplesize.html. Accessed 20 Apr 2014

24. Johns MW. Reliability and factor analysis of the Epworth sleepiness scale. Sleep. 1992;15(4):376-81.

25. Ahmed AE, Fatani A, Al-Harbi A, Al-Shimemeri A, Ali YZ, Baharoon S, et al. Validation of the Arabic version of the Epworth sleepiness scale. J Epidemiol Glob Health. 2014;4(4):297-302.

26. Hays RD, Sherbourne CD, Mazel RM. The RAND 36-item health survey 1.0. Health Econ. 1993;2(3):217-27.

27. Zhu YX, Li T, Fan SR, Liu XP, Liang YH, Liu P. Health-related quality of life as measured with the short-form 36 (SF-36) questionnaire in patients with recurrent vulvovaginal candidiasis. Health Qual Life Outcomes. 2016:14(1):65.

28. Ware JE Jr, Sherbourne CD. The MOS 36-item short-form health survey (SF-36). I Conceptual framework and item selection. Med Care. 1992;30(6):473-83.

29. Coons SJ, Alabdulmohsin SA, Draugalis JR, Hays RD. Reliability of an Arabic version of the RAND-36 health survey and its equivalence to the US-English version. Med Care. 1998:36(3):428-32.

30. Guermazi M, Allouch C, Yahia M, Huissa TB, Ghorbel S, Damak J, et al. Translation in Arabic, adaptation and validation of the SF-36 health survey for use in Tunisia. Ann Phys Rehabil Med. 2012;55(6):388-403.

31. Belayachi J, Rkain I, Rkain H, Madani N, Amlaiky F, Zekraoui A, et al. Burnout syndrome in Moroccan training resident: impact on quality of life. Iran J Public Health. 2016:45(2):260-2.

32. Sundquist J, Johansson SE. Impaired health status, and mental health, lower vitality and social functioning in women general practitioners in Sweden. A cross-sectional survey. Scand J Prim Health Care. 1999;17(2):81-6.

33. Paul F, Schredl M, Alpers GW. Nightmares affect the experience of sleep quality but not sleep architecture: an ambulatory polysomnographic study. Borderline Personal Disord Emot Dysregul. 2015;2:3.

34. Bolster $L$, Rourke $L$. The effect of restricting Residents' duty hours on patient safety, resident well-being, and resident education: an updated systematic review. J Grad Med Educ. 2015:7(3):349-63.

35. Baiardi S, La Morgia C, Sciamanna L, Gerosa A, Cirignotta F, Mondini S. Is the Epworth sleepiness scale a useful tool for screening excessive daytime sleepiness in commercial drivers? Accid Anal Prev. 2018;110:187-9.

36. Kendzerska TB, Smith PM, Brignardello-Petersen R, Leung RS, Tomlinson GA. Evaluation of the measurement properties of the Epworth sleepiness scale: a systematic review. Sleep Med Rev. 2014;18(4):321-31.

Ready to submit your research? Choose BMC and benefit from

- fast, convenient online submission

- thorough peer review by experienced researchers in your field

- rapid publication on acceptance

- support for research data, including large and complex data types

- gold Open Access which fosters wider collaboration and increased citations

- maximum visibility for your research: over $100 \mathrm{M}$ website views per year

At BMC, research is always in progress.

Learn more biomedcentral.com/submissions 